AIAA 97-3663

Mars Pathfinder Atmospheric Entry Navigation Operations

R. D. Braun

NASA Langley Research Center Hampton, VA

D. A. Spencer

P. H. Kallemeyn

R. M. Vaughan

Jet Propulsion Laboratory

Pasadena, CA

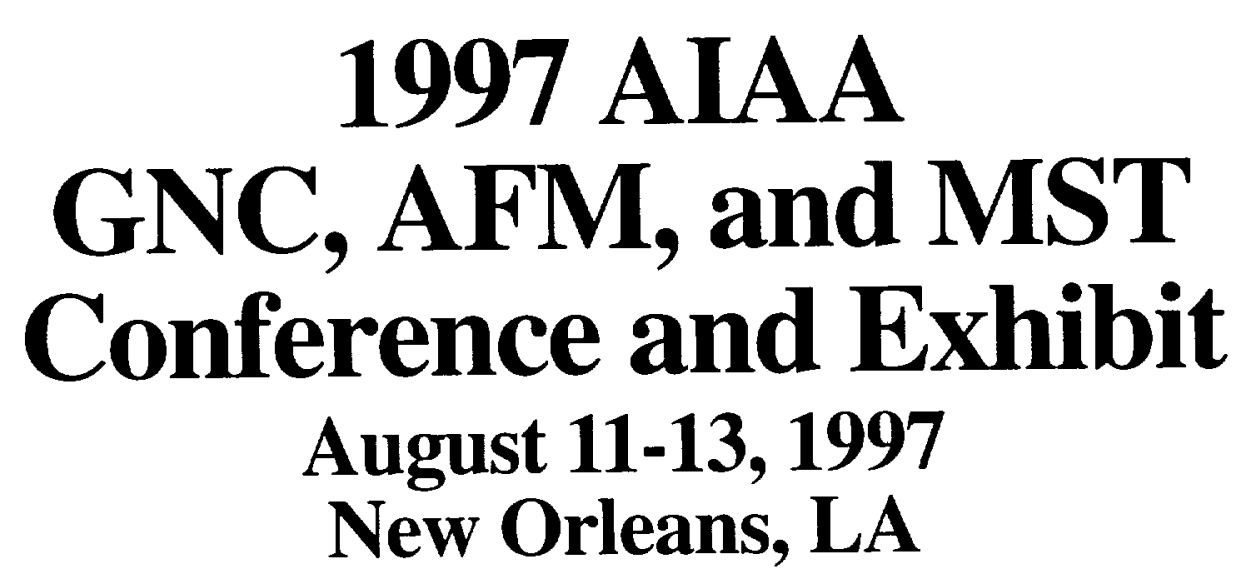

For permission to copy or republish, contact the American Institue of Aeronautics and Astronautics 1801 Alexander Bell Drive, Suite 500, Reston, VA 20191-4344 


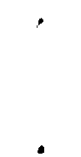




\title{
MARS PATHFINDER ATMOSPHERIC ENTRY NAVIGATION OPERATIONS
}

\author{
R.D. Braun* \\ NASA Langley Research Center \\ Hampton, VA 23681 \\ D.A. Spencer ${ }^{\dagger}$ \\ P.H. Kallemeyn ${ }^{\ddagger}$ \\ R.M. Vaughan $\dagger$ \\ Jet Propulsion Laboratory \\ Pasadena, CA 91109
}

\begin{abstract}
On July 4, 1997, after traveling close to 500 million $\mathrm{km}$, the Pathfinder spacecraft successfully completed entry, descent, and landing, coming to rest on the surface of Mars just $27 \mathrm{~km}$ from its target point. In the present paper, the atmospheric entry and approach navigation activities required in support of this mission are discussed. In particular, the flight software parameter update and landing site prediction analyses performed by the Pathfinder operations navigation team are described. A suite of simulation tools developed during Pathfinder's design cycle, but extendible to Pathfinder operations, are also presented. Data regarding the accuracy of the primary parachute deployment algorithm is extracted from the Pathfinder flight data, demonstrating that this algorithm performed as predicted. The increased probability of mission success through the software parameter update process is discussed. This paper also demonstrates the importance of modeling atmospheric flight uncertainties in the estimation of an accurate landing site. With these atmospheric effects included, the final landed ellipse prediction differs from the post-flight determined landing site by less then $0.5 \mathrm{~km}$ in downtrack.
\end{abstract}

\section{NOMENCLATURE}

g deceleration constant, 1 Earth $g=9.806 \mathrm{~m} / \mathrm{s}^{2}$

$\mathrm{g}_{1}$ first deceleration measurement, nominally $5 \mathrm{~g}, \mathrm{~g}$

$\mathrm{g}_{2}$ second deceleration measurement, nominally sampled $12 \mathrm{sec}$ after $\mathrm{g}_{1}, \mathrm{~g}$

$t_{g o}$ computed time from $g_{2}$ point to parachute deployment, sec

$\mathrm{dtdg}$ inverse of the nominal deceleration slope at $\mathrm{g}_{1}, \mathrm{sec} / \mathrm{g}$

dgdt nominal deceleration slope at $\mathrm{g}_{2}, \mathrm{~g} / \mathrm{sec}$

*Atmospheric Flight Specialist, Member, Pathfinder Operations Navigation Team, NASA Langley.

$\uparrow$ Member, Pathfinder Operations Navigation Team, JPL. ${ }^{\ddagger}$ Chief, Pathfinder Operations Navigation Team, JPL.

Copyright $\odot 1997$ American Institute of Aeronautics and Astronautics, Inc. No copyright is asserted in the United States under Title 17, U.S. Code. The U.S. Government has a royaltyfree license to exercise all rights under the copyright claimed herein for Governmental purposes. All other rights are reserved by the copyright owner. $\mathrm{g}_{2 \mathrm{a}}$

$\mathrm{g}_{2 \mathrm{~b}}$

tgo2a

$t_{\text {go } 2 b}$

$\gamma$ minimum acceptable $g_{2}$ deceleration measurement, $\mathrm{g}$ maximum acceptable $\mathrm{g}_{2}$ deceleration measurement, $\mathrm{g}$ maximum acceptable $t_{\text {go }}$ computation, sec minimum acceptable $t_{\text {go }}$ computation, sec atmospheric entry flight-path angle, deg

\section{INTRODUCTION}

On July 4 1997, the Pathfinder spacecraft ushered in a new era of planetary exploration by successfully landing on the surface of Mars. The primary objective of the Pathfinder mission was to develop and demonstrate a lowcost, reliable system for landing on the surface of Mars. ${ }^{1}$ In addition to this engineering objective, a focused set of science investigations were performed and several technology elements required for further exploration of Mars were demonstrated..$^{2-4}$

In the present paper, the atmospheric entry and approach navigation activities required to support Pathfinder's entry, descent, and landing operations are discussed. These trajectory simulation analyses were applied by members of the Pathfinder operations navigation team to ensure successful parachute deployment and estimate the Pathfinder landing site. While the July 4 entry sequence was autonomous, ground controllers had numerous opportunities to update onboard software parameters and adjust the atmospheric entry conditions during interplanetary cruise.

The analysis tools used in entry operations were developed in the spacecraft design and development phase and used to prescribe spacecraft test conditions prior to launch. The validity of these analyses is currently being analyzed through post-flight trajectory reconstruction. ${ }^{5}$ After a brief mission summary, the present paper contains an overview of the atmospheric analysis tools, a discussion of the parachute deployment algorithm developed with these simulation analyses, and a description 
of their use by the Pathfinder operations navigation team in the days preceding the spacecraft's July 4 entry, descent, and landing. Insight into the performance of the Pathfinder parachute deployment system based on a preliminary assessment of the flight data is also presented.

\section{MISSION OBJECTIVES}

The primary engineering objective of Pathfinder, acquisition and return of data on the entry, descent, and landing system as well as lander performance, was completed a few hours after landing. Other objectives, including deployment of the Sojourner rover, were completed on July 5, 1997. Figure 1 shows the lander on the surface of Mars on July 4, 1997; whereas, Fig. 2 is an image taken by the rover of the lander after its deployment. While the primary mission duration for the rover and lander was 1 week and 1 month respectively, there is nothing to preclude longer operations. In fact, both systems have already surpassed this expectation, yielding a rich scientific harvest.

The Pathfinder science payload is comprised of the Sojourner rover, an alpha-proton $\mathrm{X}$-ray spectrometer mounted on Sojourner, a mast-mounted 360-degree ste-

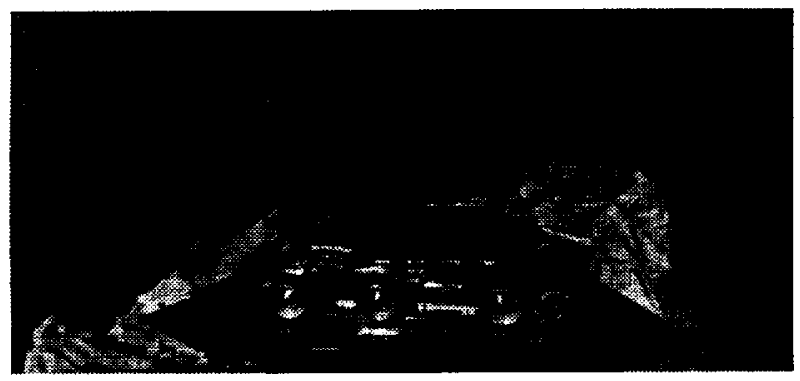

Fig. 1: Pathfinder spacecraft on the Mars surface, July 4, 1997.

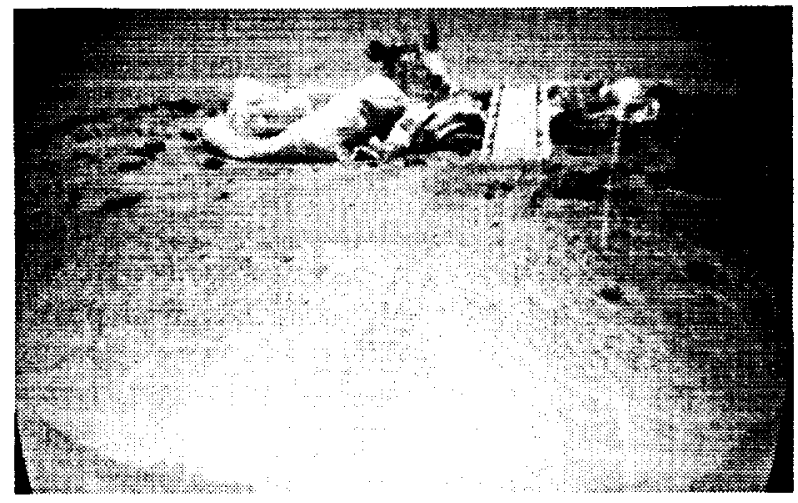

Fig. 2: View of the Pathfinder lander (Sagan Memorial Station) from the Sojourner rover.

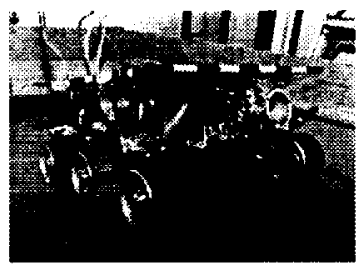

APXS

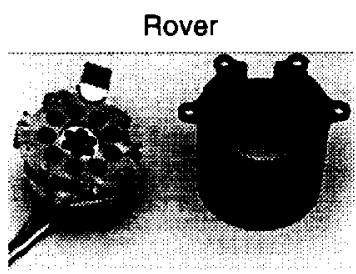

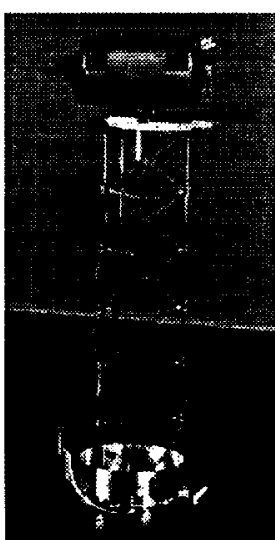

IMP

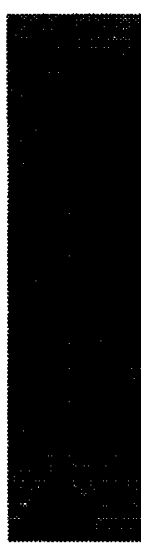

ASI/MET
Fig. 3: Mars Pathfinder science instruments.

reo imager, and an atmospheric science/meteorology station. These instruments, depicted in Fig. 3, have permitted investigation of the landing site geology and surface morphology, the magnetic and mechanical properties of the surface materials, determination of the atmospheric structure, and insight into the rotational and orbital dynamics of the planet (inferred from high-gain antenna tracking). ${ }^{6}$

As shown in Fig. 4, the Pathfinder spacecraft was targeted for a landing within a $100 \times 200 \mathrm{~km}$ ellipse in the Ares Vallis floodplain region of Mars centered at 19.24 $\mathrm{N}$ latitude, 33.1 W longitude. This landing site is approximately $850 \mathrm{~km}$ southeast of the Viking 1 Lander. An Ares Vallis landing was selected for several reasons, including spacecraft and rover design constraints, entry, descent, and landing concerns, scientific potential, and safety. ${ }^{7}$ Engineering factors which affected this choice of landing site included the desire for a low surface el-

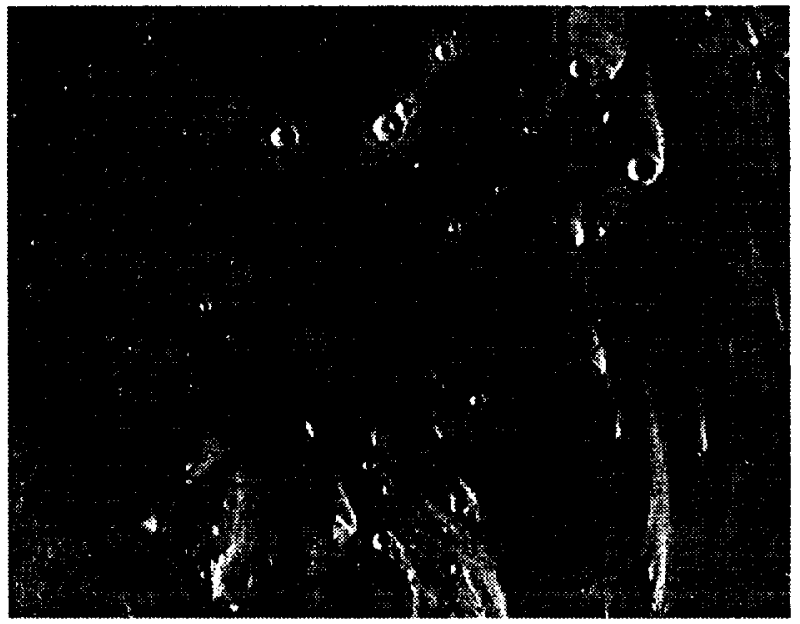

Fig. 4: Ares Vallis landing site. 
evation (to allow sufficient parachute deceleration time), high Earth and Sun elevation angles (for improved communication and power), and a relatively flat region free of surface hazards such as large craters, chasms, or knobs (for improved airbag performance). From a science perspective, this site was deemed favorable since a variety of rock and soil types thought to be deposited by an ancient catastrophic flood were expected.

\section{THE ROUTE TO MARS}

The Pathfinder spacecraft began its 7-month journey to Mars with the launch of its Delta-II 7925 rocket from Cape Canaveral, Florida on December 4, 1996. To satisfy numerous mission constraints a Type I interplanetary trajectory was selected with a heliocentric transfer angle of $155 \mathrm{deg}{ }^{8}$ Among these mission constraints, the requirement of a pre-dawn landing in the Northern hemisphere dictated a retrograde atmospheric entry at Mars (with the drawback of increasing the vehicle's velocity relative to the atmosphere by approximately $0.43 \mathrm{~km} / \mathrm{s}$ relative to a similar posigrade entry). During its interplanetary cruise, a series of four trajectory correction maneuvers were executed as shown in Fig. $5 .^{9}$ As discussed in a subsequent section, a contingency fifth trajectory correction maneuver could have been performed at either entry -10 or entry -5 hours; however, when these decision points approached (entry -11 and entry -7.5 hours), the flight team deemed this maneuver unnecessary.

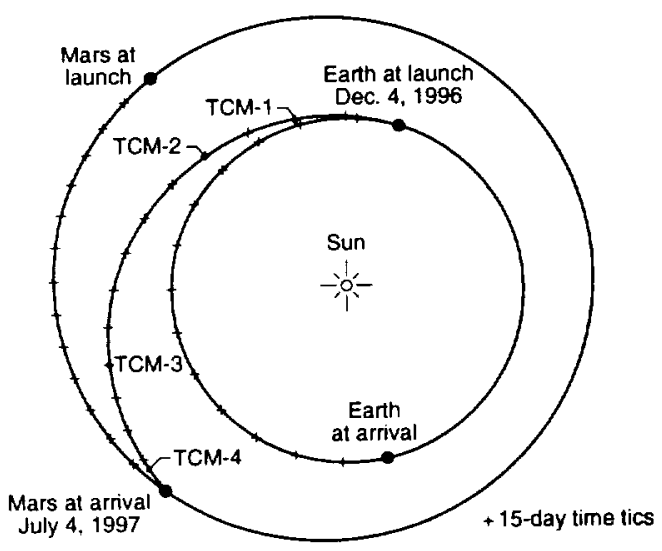

Fig. 5: Mars Pathfinder interplanetary trajectory.

As shown in Fig. 5, the total transit time for the Pathfinder spacecraft was 210 days in which the vehicle traveled approximately $5.0 \mathrm{e}+08 \mathrm{~km}$ along an ellipsoidal arc about the Sun. From an orbit determination analysis based on all available Deep Space Network tracking data at the time of entry, the best-estimated Mars atmospheric entry conditions were derived and are presented in Table 1. In this table, both the inertial and relative velocity estimates are given. At entry, the spacecraft had a mass of $585.3 \mathrm{~kg}$ and a ballistic coefficient of $62.4 \mathrm{~kg} / \mathrm{m}^{2}$.

\section{Table 1: Mars Pathfinder best-estimated atmospheric entry conditions (10:00 am PDT, 7/4/97)}

Radius, km 3522.200

Declination, deg

22.630

West Longitude, deg

21.831

Inertial velocity, $\mathrm{km} / \mathrm{s}$

7.264

Inertial flight-path angle, deg

$-14.060$

Inertial azimuth angle, deg

253.148

Relative velocity, $\mathrm{km} / \mathrm{s}$.

7.479

Relative flight-path angle, deg

$-13.649$

Relative azimuth angle, deg .

253.675

\section{ENTRY, DESCENT, AND LANDING}

The Pathfinder spacecraft utilized a low-cost but complex entry, descent, and landing (EDL) strategy to survive its flight through the Mars atmosphere. As shown in Fig. 6, four deceleration mechanisms (aeroshell, parachute, solid-rockets, and airbags) were used to slow the spacecraft from its interplanetary approach velocity $(7.48$ $\mathrm{km} / \mathrm{s}$ relative to the atmosphere) to its final velocity of zero. As shown in Fig. 7, entry, descent, and landing was initiated thirty minutes prior to encountering the atmospheric interface (defined at a radius of $3522.2 \mathrm{~km}$ ) when the cruise-stage was jettisoned. The aeroshell encountered a peak heat rate of approximately $100 \mathrm{~W} / \mathrm{cm}^{2}$

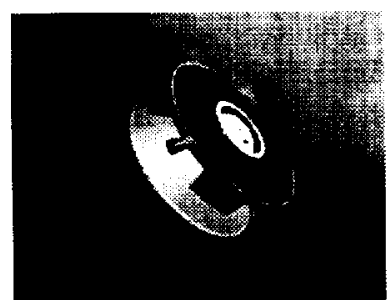

Cruise-Stage Separation

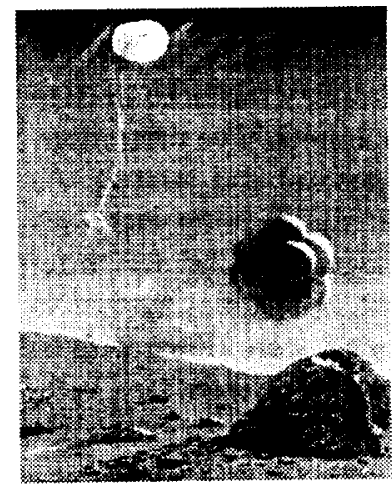

Landing

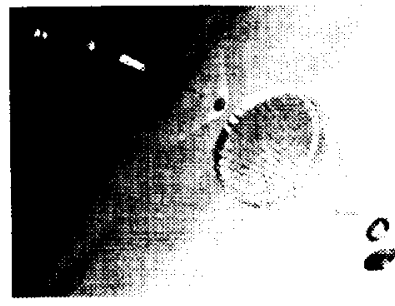

Entry and Descent

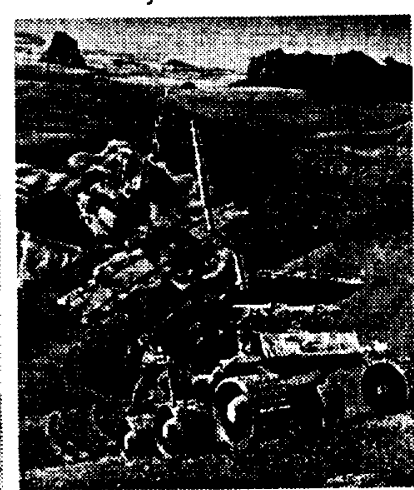

Surface Operations
Fig. 6: Pathfinder entry, descent, and landing system. 


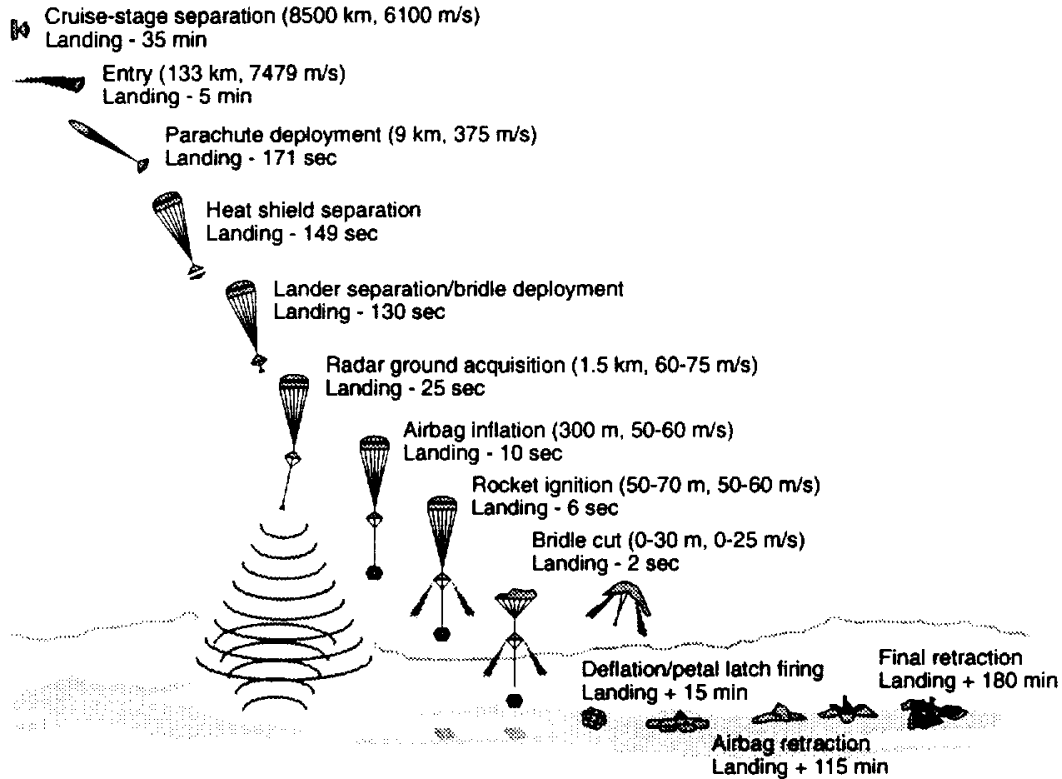

Fig. 7: Entry, descent, and landing sequence of events (reconstructed from flight data).

and a peak deceleration of $16 \mathrm{~g}$ approximately 70 and $78 \mathrm{sec}$ after encountering the Mars atmosphere. The parachute was unfurled $171 \mathrm{sec}$ past the entry interface. Release of the forebody heatshield and extension of the bridle followed 22 and $41 \mathrm{sec}$ after parachute deployment. Once the spacecraft traveled down the bridle, the radar altimeter initiated the search for the Mars surface (at a surface altitude of approximately $1.5 \mathrm{~km}$ ). This altimeter data was then used to infer the descent rate and determine the appropriate time of airbag inflation (296 sec past the atmospheric interface) and solid-rocket ignition ( $300 \mathrm{sec}$ past the atmospheric interface). After the three solid-rocket motors were fired to delete the remaining vertical velocity, the bridle was cut (at an altitude of $21 \mathrm{~m}$ above the surface). The spacecraft then fell to the surface (first impact at $306 \mathrm{sec}$ past the atmospheric interface) bouncing more than 15 times before coming to a roll-stop.

Pathfinder's direct-entry strategy was in contrast to the Viking approach in which a propulsive orbit insertion was performed prior to descent and landing. As shown in Fig. 8, this decision significantly increased Pathfinder's entry velocity, magnifying the design requirements on the entry, descent, and landing system. In addition, while the Viking landers were flown with an offset center-of-mass to achieve a lifting trajectory, Pathfinder entered the Mars atmosphere at a near zero angle of attack to increase its drag force (reduce its ballistic coefficient) and simplify the design. In another simplification over Viking's active control strategy, Pathfinder's flight at near zero angle of attack was main-

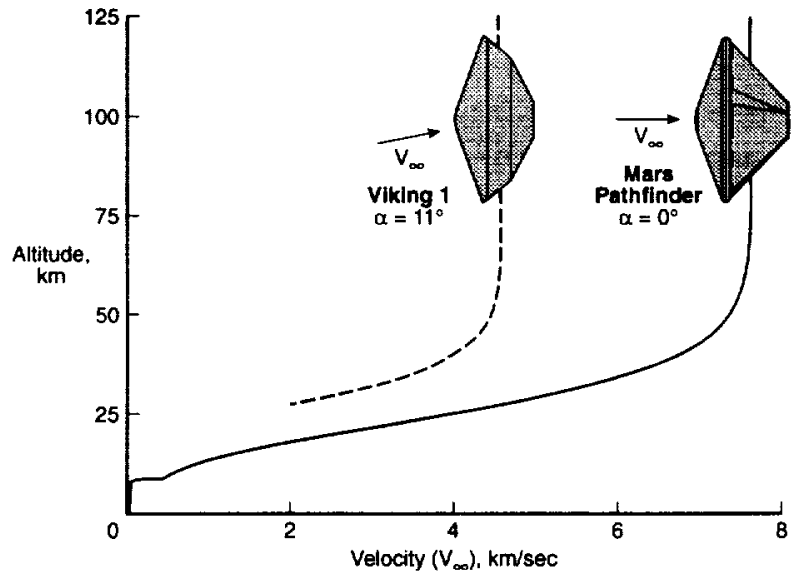

Fig. 8: Mars Pathfinder and Viking atmospheric entry comparison.

tained without propulsion. Instead, this angular orientation was enforced through reliance on a $2 \mathrm{rpm}$ spin rate and the inherent aerodynamic stability of the 70 degree sphere-cone aeroshell. ${ }^{10}$

\section{ENTRY ANALYSIS}

Independent simulations of the Pathfinder entry, descent, and landing flight dynamics were developed at the Jet Propulsion Laboratory and the NASA Langley Research Center. At JPL, a three-degree-of-freedom translational equation of motion simulation was developed with use of the Atmospheric Entry Program (AEP). ${ }^{11}$ This simulation spanned the entire entry, de- 
scent, and landing sequence (from the entry interface to landing). Additionally, the parachute descent and landing phases of the mission were analyzed with the Automated Dynamic Analysis of Mechanical Systems (ADAMS) multi-body simulation program in which both the translational and rotational equations of motion were solved. ${ }^{12}$ At NASA-Langley, the six-degree-of-freedom version of the Program to Optimize Simulated Trajectories $^{13}$ (6D POST) was used to analyze both the translational and rotational equations of motion from the atmospheric interface to parachute deployment. The three-degree-of-freedom version of POST was then used to simulate the parachute descent and landing phases of atmospheric flight.

When coupled with the JPL orbit determination software (interplanetary cruise), this suite of atmospheric simulation tools provided a wide range of analysis capabilities. While the 6D POST and ADAMS simulations were believed to yield more accurate flight predictions (as a result of the more complete dynamic modeling), the three-degree-of-freedom AEP and POST simulations were used to provide an independent check of the higher fidelity results as well as rapid analysis capability. Good agreement in regard to the heating rate, parachute deployment time, and other trajectory events was typical among this suite of Pathfinder-specific atmospheric analyses.

The simulations relied on a consistent set of physical models. ${ }^{14}$ Atmospheric density and pressure profiles derived from Hubble Space Telescope and Earth-based microwave measurements of the Mars atmospheric temperature were employed. ${ }^{15}$ Prior to entry, this model indicated that the atmosphere was likely to be significantly cooler with a lower dust content than the atmosphere observed by the Viking landers. Updates to this atmospheric model were performed during interplanetary cruise as part of the entry operations procedure. A six-degree-of-freedom aerodynamic model developed from a combination of computational fluid dynamic calculations and existing wind-tunnel and ballistic-range data was employed. ${ }^{10}$ This aerodynamic database was valid from entry (in the free molecular flow regime) to parachute deployment. After parachute deployment, aerodynamic drag predictions from Pioneer Aerospace (the parachute manufacturer) were used. ${ }^{15}$ In the ADAMS multi-body simulation, additional aerodynamic relations were derived. ${ }^{12}$

The JPL and LaRC simulations were developed in the spacecraft design phase and utilized throughout the Pathfinder program in a Monte Carlo fashion to statistically assess the impact of a range of off-nominal conditions on the flight system. ${ }^{17,18}$ Outputs from these Monte-
Carlo simulations were used in the design of the Pathfinder heatshield, the entry, descent, and landing flight soft ware, and to define numerous sets of hardware tests. ${ }^{19}$ In addition, these simulation results were imported into JPL's spacecraft testbed and used to evaluate the performance of the entry, descent, and landing flight software for a range of off-nominal atmospheric flight conditions.

In the operations mode, the 6D POST, 3D POST, and AEP simulations were used by the navigation team to update the estimation of the atmospheric flight conditions. Changes in Pathfinder's estimated atmospheric flight were expected as a result of improved estimates of the atmospheric model and atmospheric interface state vector as the spacecraft approached Mars. By modifying the entry, descent, and landing flight software parameters, the operations team could inform the spacecraft of its most likely atmospheric flight conditions. Without this update capability, the likelihood of a successful entry, decent, and landing (particularly, a successful parachute deployment) would have been adversely affected. As a result, these atmospheric flight simulations were employed at numerous opportunities preceding Pathfinder's entry, descent, and landing to update the onboard set of flight software parameters and estimate the landing site. This update process was one of the primary responsibilities of the operations navigations team in the days prior to landing.

\section{ENTRY, DESCENT, AND LANDING FLIGHT SOFTWARE PARAMETERS}

\section{Parachute Deployment Software Parameters}

Pathfinder's entry, descent, and landing software was responsible for autonomously guiding the spacecraft from cruise-stage separation to a successful landing. Much of this sequence was timed by processes running in the flight computer, with events being triggered by pyrotechnic firings. Both a primary and backup system were developed to initiate deployment of the parachute. Without the luxury of an inertial measurement unit or gyroscopes, the primary parachute deployment algorithm relied solely on accelerometer readings and consultation of a pre-determined set of entry deceleration profiles, stored in curve-fit form. ${ }^{20,21}$ This algorithm was initiated at cruise-stage separation and was responsible for interpreting the deceleration pulse, scheduling the appropriate time to initiate parachute deployment, and firing the parachute mortar.

The primary algorithm relied on initiation of a timer when the deceleration level reached $5 \mathrm{~g}$. This is termed the $\mathrm{g}_{1}$ 


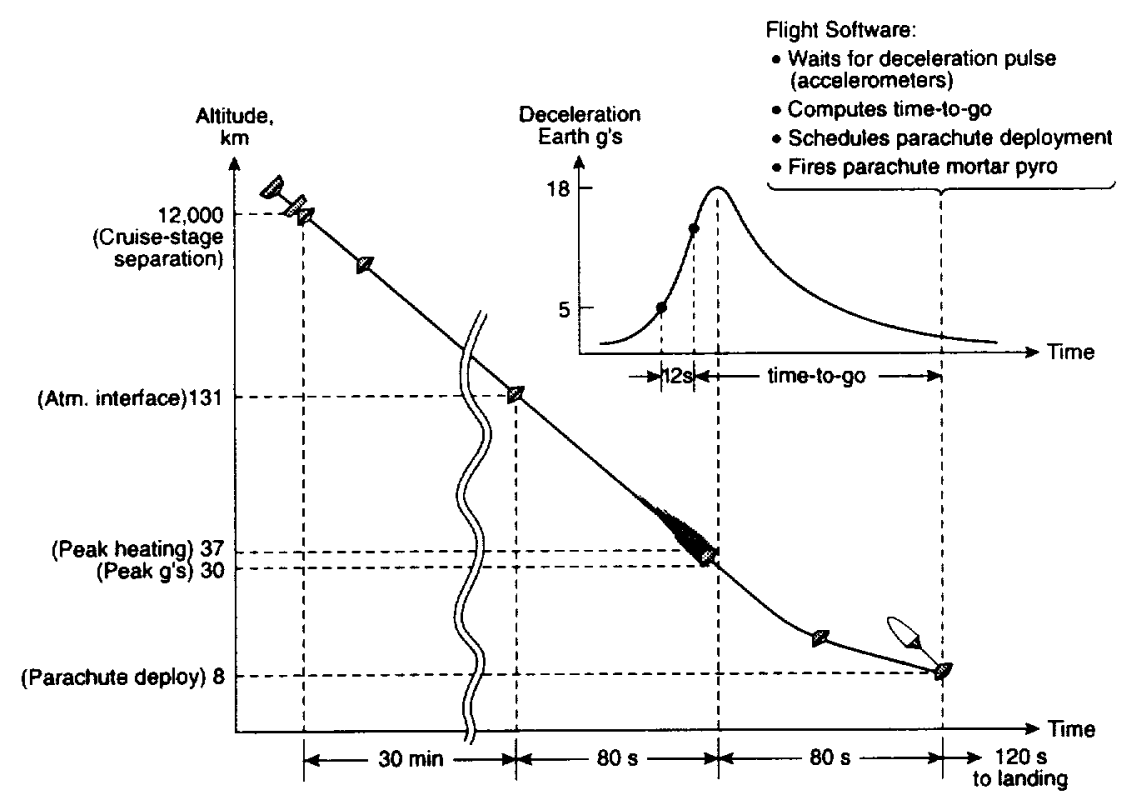

Fig. 9: Pathfinder flight software parachute deployment process.

point. Twelve seconds after this timer initiation, a second deceleration measurement was taken $\left(\mathrm{g}_{2}\right)$. Based on the $\mathrm{g}_{2}$ deceleration value, the onboard curve-fit was consulted to determine the time remaining until the parachute could be safely deployed $\left(\mathrm{t}_{\mathrm{go}}\right)$. This onboard process is illustrated in Fig. 9. As shown in Fig. 10, for the expected range of entry flight-path angles $(-14.2 \pm 1.0$ $\mathrm{deg}$ ), a diverse set of deceleration profiles were expected, resulting in a relatively large range of parachute deployment times.

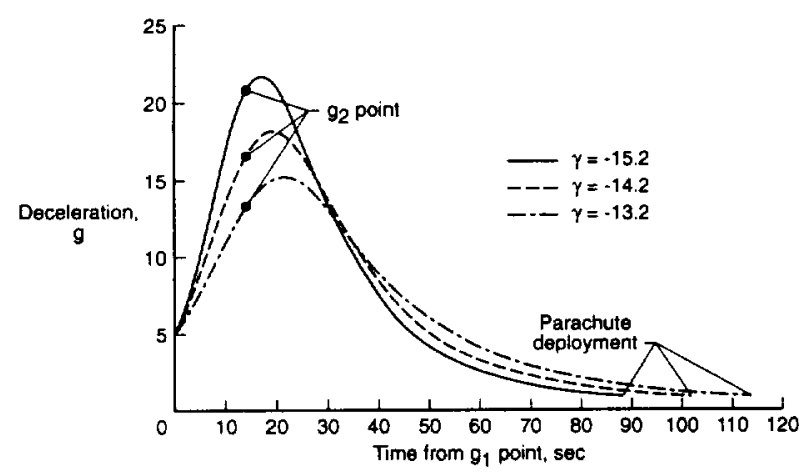

Fig. 10: Range of deceleration profiles accommodated by parachute deployment algorithm.

The objective of this in-flight software process was to deploy the parachute as close to a dynamic pressure of $600 \mathrm{~N} / \mathrm{m}^{2}$ as possible. Design requirements for the parachute included a dynamic pressure below $703 \mathrm{~N} / \mathrm{m}^{2}$ and a Mach number greater than 1.2 . The $600 \mathrm{~N} / \mathrm{m}^{2}$ parachute deployment target was determined iteratively through Monte-Carlo simulation, and maintained the 3- sigma high dynamic pressure below the $703 \mathrm{~N} / \mathrm{m}^{2}$ design limit while providing sufficient time for the remaining elements of the descent and landing sequence to occur nominally. Pre-launch Monte-Carlo simulations ${ }^{18}$ predicted a $99.7 \%$ probability of successful parachute deployment if the primary algorithm was successfully employed.

The entry deceleration curve-fit used in this process was derived from a set of six-degree-of-freedom POST simulations specifically tuned to the latest entry state prediction and atmospheric model. The POST simulations were initiated with a dispersed set of entry states, terminating at $600 \mathrm{~N} / \mathrm{m}^{2}$. These dispersed entry states were obtained by sampling the orbit determination covariance at $0.1 \mathrm{deg}$ entry flight-path angle increments. The maximum dispersion was defined by the three-sigma uncertainty in the orbit determination solution. As an example, the curve-fit loaded during spacecraft cruise is shown in Fig. 11. This linear curve-fit was estimated from a least-squares fit to the $6 \mathrm{D}$ POST data resulting in the following equation:

$$
\mathrm{t}_{\mathrm{go}}=\left(40.14242-\mathrm{g}_{2}\right) / 0.28033
$$

This least-squares information was relayed to the spacecraft through two $\left(\mathrm{g}_{2}, \mathrm{tgo}_{\mathrm{go}}\right)$ coordinates - a minimum $\left(g_{2 a}\right)$ and maximum $\left(g_{2 b}\right)$ expected value, 11 and 21 respectively. Using these values in the above equation, the minimum ( $\mathrm{tgob}_{\mathrm{gob}}$ ) and maximum ( $\mathrm{t}_{\mathrm{goa}}$ ) may be computed as 68.284 and $103.956 \mathrm{sec}$ respectively. In addition to defining the $t_{g o}$ curve-fit, the $g_{2 a}$ and $g_{2 b}$ values were 


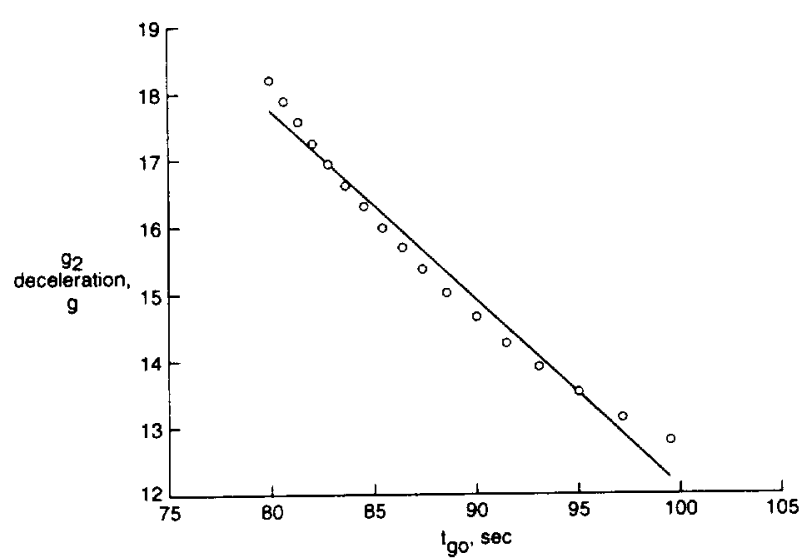

Fig. 11: Parachute deployment tgo curve-fit onboard spacecraft prior to EDL parameter update \#1.

also used to determine the validity of the accelerometer measurements during flight. As part of the fault protection process, the primary algorithm was assumed to be invalid if the $g_{2}$ measurement was outside of the range of vales specified by $g_{2 a}$ and $g_{2 b}$. Similarly, the computed $t_{g o}$ was assumed to be invalid if it was outside the range specified $t_{\text {goa }}$ by and $t_{\text {gob. }}$.

Due to the $8 \mathrm{hz}$ flight software sampling frequency of the accelerometer measurements and potential data corruption, the $\mathrm{g}_{1}$ and $\mathrm{g}_{2}$ measurements may not occur precisely at $5 \mathrm{~g}$ and 12 seconds later. Hence, fault-tolerant procedures were developed to estimate the true time at the $g_{1}$ point and the associated $g_{2}$ value $12 \mathrm{sec}$ later. Windows, $1.5 \mathrm{~g}$ and $1.5 \mathrm{sec}$ in duration, were established for the primary system to obtain valid data. If the system did not obtain a valid measurement in either of these windows, the backup parachute deployment algorithm would be enabled. Errors in the obtained measurements were minimized and the performance of the primary algorithm was enhanced by extrapolating from the true measurements to the desired times along pre-determined slopes ( $\mathrm{dtdg}$ at the $\mathrm{g}_{1}$ point and dgdt at the $\mathrm{g}_{2}$ point).

If the flight software determined that accelerometer readings were invalid, the backup parachute deployment system would be enabled. This system initiates deployment of the parachute at a fixed time, stored as a flight software parameter. ${ }^{22}$ Pre-launch Monte-Carlo simulations ${ }^{18}$ predicted a $90 \%$ probability of successful parachute deployment if the secondary system was employed and updates to this fixed-time strategy were performed as the spacecraft approached Mars.

To minimize risk, parameter updates to the primary and secondary parachute deployment systems were designed into the operations navigation procedures. Soft- ware parameters which determined the primary system's curve-fit, fault-protection logic, and deceleration sampling strategy as well as the fixed-time backup could be updated during flight (prior to entry). Update criteria and command approval strategies were also established and simulated in several operations readiness tests. Parameter updates were expected as the spacecraft's entry state and predicted atmosphere varied.

\section{Predicted Landing Site Parameters}

The estimated landing site latitude and longitude were also loaded into the flight software as parameters which could be updated prior to encountering the Mars atmosphere. This landing site position estimate was used by the lander during surface operations to orient the highgain antenna for Earth communications. The position accuracy required for successful high-gain antenna pointing was approximately $1.0 \mathrm{deg}(60 \mathrm{~km})$. A parameter update to the landed estimate would have been required during cruise had the best-estimated landing site moved out of this $60 \mathrm{~km}$ tolerance.

\section{ENTRY OPERATIONS}

As shown in Fig. 12, the operations navigation function was most critical in the 36 hours preceding entry, descent, and landing. In this period, four opportunities to update the entry, descent, and landing software parameters and two opportunities to perform a contingency trajectory correction maneuver (TCM-5) existed. This final navigation function ended at approximately 6 am PDT on July 4 (entry -4 hours).

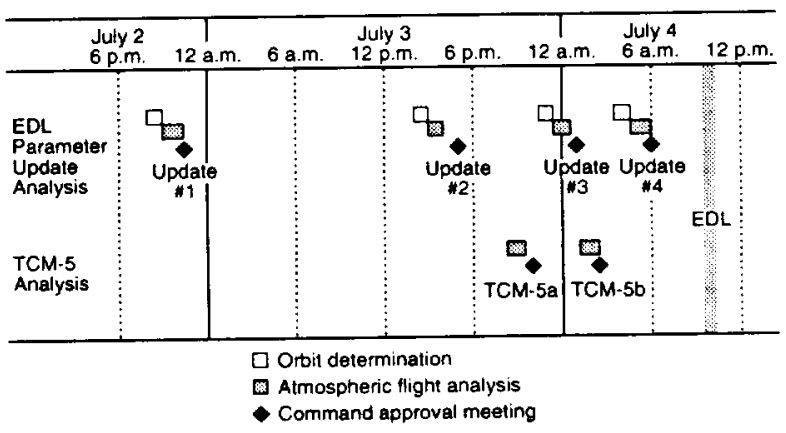

Fig. 12: Operations navigation function timeline preceding atmospheric entry.

\section{EDL Update \#1}

At approximately 8:00 pm PDT on July 2, 1997 (entry -38 hours) entry, descent, and landing update \#I was initiated. This ground analysis process began by performing orbit determination with the latest tracking data 
included in the analysis. From this solution, a best-estimated trajectory was produced in which the entry flight-path angle was $-13.942 \mathrm{deg}$. At this point in time, the entry covariance predicted a three-sigma flight-path angle uncertainty of $\pm 0.8 \mathrm{deg}$. With this covariance a dispersed set of entry states were generated and six-degree-of-freedom atmospheric trajectory simulations were computed from the entry interface to the nominal parachute deployment point $\left(600 \mathrm{~N} / \mathrm{m}^{2}\right.$ dynamic pressure). For each trajectory, the $g_{2}$ deceleration value and the $t_{g o}$ were computed, stored, and plotted. As shown in Fig. 13, a least-squares curve was then fit to this data for potential transmission to the spacecraft. At update $\# 1$, this linear least-squares fit produced the following equation:

$$
\mathrm{t}_{\mathrm{go}}=\left(34.51997-\mathrm{g}_{2}\right) / 0.21802
$$

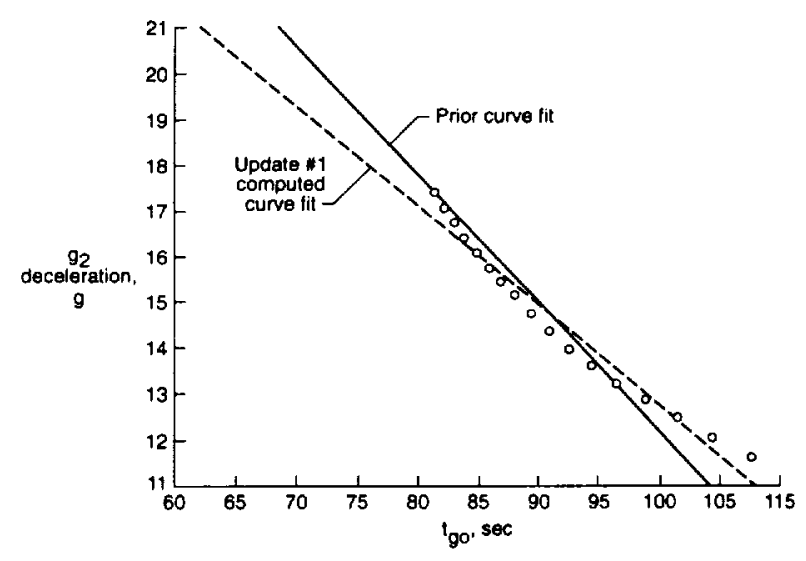

Fig. 13: Parachute deployment $t_{g o}$ curve-fit loaded onto spacecraft as a result of EDL parameter update \#I process.

The resulting values of $t_{\text {goa }}$ and $t_{\text {gob }}$ are $107.880 \mathrm{sec}$ and $62.012 \mathrm{sec}$ corresponding to a $\mathrm{g}_{2 \mathrm{a}}$ of $11.0 \mathrm{~g}$ and a $\mathrm{g}_{2 \mathrm{~b}}$ of $21.0 \mathrm{~g}$, respectively. This data is plotted in Fig. 13 which also presents the parachute deployment curve-fit which was loaded onboard the spacecraft at the time of this update opportunity. As shown in this figure, for the best-estimated flight-path angle at entry -38 hours, (a $\mathrm{g}_{2}$ deceleration of 14.741 ), the onboard and current estimates of the nominal parachute deployment time differ by only $0.11 \mathrm{sec}$. In this case, such good agreement occurs because the best-estimated trajectory falls in the region where the two curve-fits fortuitously cross. For another entry angle, for example $-14.06 \mathrm{deg}$ where the $\mathrm{g}_{2}$ deceleration value is 12.482 , the two curve-fits disagree by approximately $2 \mathrm{sec}$ with the update \#1 curve-fit implying a later parachute deployment $\left(t_{\text {go }}=101.082\right)$.

The best-estimated trajectory was then examined in detail such that values of dtdg and dtdg could be esti- mated ( 1.660 and 0.745 respectively). Verification of the best-estimated $6 \mathrm{D}$ POST trajectory solution was performed through comparison with an AEP solution. The nominal parachute deployment time obtained from these two solutions differed by $1.95 \mathrm{sec}$ (approximately 30 $\mathrm{N} / \mathrm{m}^{2}$ in dynamic pressure) which was within the specified tolerance. The backup parachute deployment time was then inferred from the $6 \mathrm{D}$ POST best-estimated trajectory (16:54:34.612 UTC, or 164.11 sec from the atmospheric interface).

To determine if a parameter update was warranted, the current set of software parameters was compared to the onboard set as shown in Table 2. Pre-flight criteria had been established on the three most critical EDL parameters. These general criteria stated that an EDL parameter update would occur if either the primary or backup parachute deployment time was predicted as being in error by more than $3 \mathrm{sec}$ for the best-estimated trajectory or if the predicted landing site was off by more than $1.0 \mathrm{deg}$ ( $60 \mathrm{~km}$ from the onboard value (for high-gain antenna pointing accuracy). As shown in Table 2, at entry -38 hours, without modification, the onboard backup parachute deployment timer would have deployed almost 9

Table 2. Entry, Descent, and Landing Software Parameter Update \#I

\begin{tabular}{|c|c|c|c|}
\hline $\begin{array}{c}\text { Parachute } \\
\text { Deployment } \\
\text { Parameter }\end{array}$ & $\begin{array}{c}\text { Values } \\
\text { Estimated in } \\
\text { Update Process }\end{array}$ & $\begin{array}{c}\text { Currently } \\
\text { Loaded } \\
\text { Values } \\
\end{array}$ & $\begin{array}{c}\text { Difference } \\
\text { (Update } \\
\text { Criterion) } \\
\end{array}$ \\
\hline $\begin{array}{l}\text { Primary algorithm } \\
\text { parachute deploymen } \\
\text { time, sec }\end{array}$ & 164.12 & 164.01 & $0.11(3.0)$ \\
\hline $\begin{array}{l}\text { Fixed-time backup } \\
\text { (UTC) }\end{array}$ & $16: 54: 34.612$ & $16: 54: 25.691$ & $8.92(3.0)$ \\
\hline $\begin{array}{l}g_{1} \text { target } \\
\text { deceleration, } g\end{array}$ & 5.0 & 5.0 & \\
\hline $\begin{array}{l}g_{1} \text { to } g_{2} \text { target } \\
\text { interval, sec }\end{array}$ & 12.0 & 12.0 & \\
\hline$g_{2 a}$ & 11.0 & 11.0 & \\
\hline$t_{\text {goa }}$ & 107.880 & 103.956 & \\
\hline$g_{2 b}$ & 21.0 & 21.0 & \\
\hline$t_{g o b}$ & 62.012 & 68.284 & \\
\hline dtdg @ $g_{1}$ point & 1.66 & 1.60 & \\
\hline$d g d t @ g_{2}$ point & 0.745 & 0.84 & \\
\hline $\begin{array}{l}\text { High-Gain } \\
\text { Antenna } \\
\text { Parameter }\end{array}$ & $\begin{array}{c}\text { Value } \\
\text { estimated } \\
\text { in update } \\
\text { process }\end{array}$ & $\begin{array}{c}\text { Currently } \\
\text { loaded } \\
\text { value }\end{array}$ & \\
\hline $\begin{array}{l}\text { Latitude, } \\
\text { Longitude }\end{array}$ & $\begin{array}{l}18.82 \\
326.32\end{array}$ & $\begin{array}{l}19.2438 \\
326.9000\end{array}$ & $\begin{array}{c}0.69^{\circ}\left(1.0^{\circ}\right) \\
41.0 \mathrm{~km} \\
(60 \mathrm{~km})\end{array}$ \\
\hline
\end{tabular}


sec early. Such a large error was a result of the more shallow entry angle, an update to the atmospheric model, and bit cutoff errors made in the onboard set of commands. As a result, a parameter update was deemed necessary. After a command approval meeting, the Table 2 parameters were relayed to the Pathfinder spacecraft at on July 2, 1997 at approximately 11:00 pm PDT.

While the ground analyses for EDL update processes 2-4 were all performed, the spacecraft remained close to its predicted path. As an example, as these opportunities passed, the best-estimated entry flight-path angle was $-13.942,-13.902,-13.896$, and $-13.914 \mathrm{deg}$ at the four update opportunities. As a result, no further EDL software modifications were relayed to the spacecraft. Hence, the EDL parameters presented in Table 2, Fig. 13, and equation 2 were the onboard set used during Pathfinder's atmospheric flight.

\section{Landing Site Prediction and TCM-5}

As discussed previously, four trajectory correction maneuvers (TCM) were designed into the nominal Pathfinder flight profile. As a result of planetary protection requirements, the first of these to actually place the spacecraft on an intercept trajectory with Mars was TCM-3. After performing this $11.0 \mathrm{~cm} / \mathrm{s} \Delta V$ on May 6,1997 , orbit determination solutions indicated that the Pathfinder was on a trajectory with a steeper atmospheric entry flight path angle than desired. At this point, the predicted entry flight-path angle was $-14.84 \mathrm{deg}$; whereas, an entry flight-path angle of $-14.2 \mathrm{deg}$ was desired. As shown in Fig. 14, this resulted in a landing site prediction roughly equal in size, but offset to the northeast of the science requirement ellipse. Hence, prior to TCM-4, approximately $60 \%$ of the predicted landing ellipse did not meet

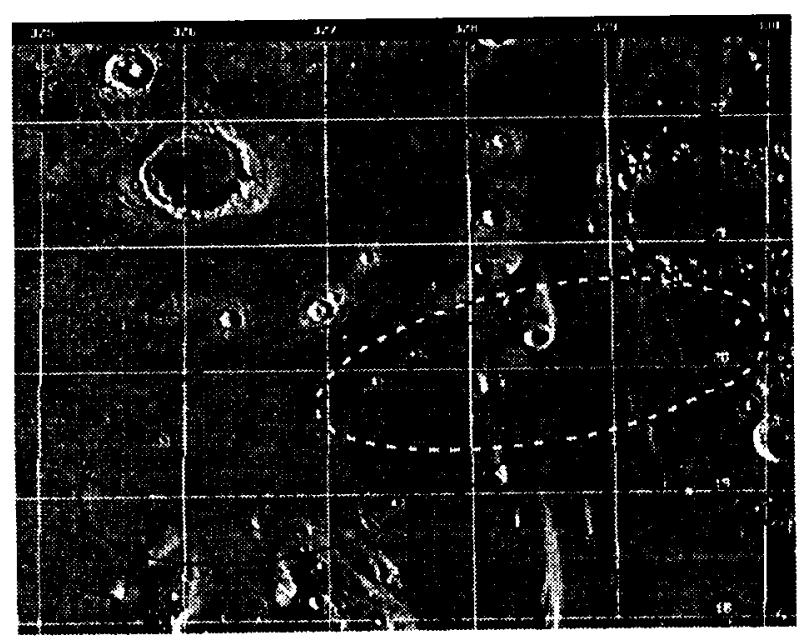

Fig. 14: Post TCM-3 landing site prediction. the mission requirements. Note that the ellipse shown in Fig. 14 represents a three-sigma prediction; that is, a $99.7 \%$ probability existed that without further maneuvers the final landing site would be within this predicted region.

The fourth trajectory correction maneuver was executed on June 25,1997 . This $1.8 \mathrm{~cm} / \mathrm{s}$ maneuver placed the spacecraft very close to its nominal path (best-estimated entry flight-path angle of $-14.18 \mathrm{deg}$ ). Furthermore, after completion of this maneuver, the predicted landing ellipse was completely contained within the science requirement ellipse measuring approximately $180 \times 70 \mathrm{~km}$. This landing site prediction is shown in Fig. 15.

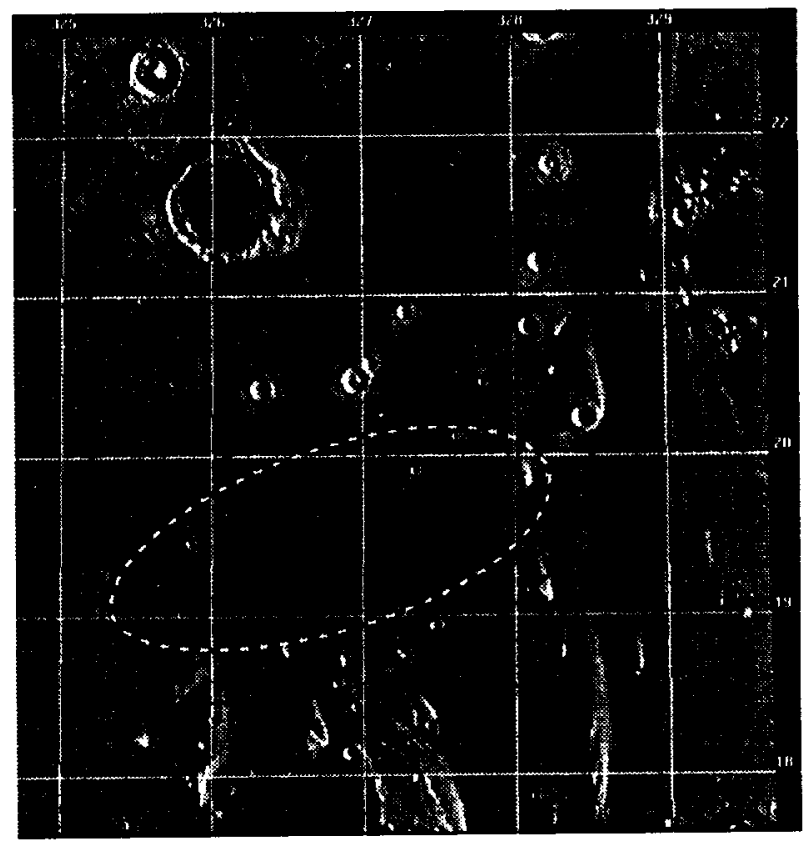

Fig. 15: Post TCM-4 landing site prediction.

As Pathfinder approached Mars, small changes in its predicted landing site were expected as a result of increased state knowledge (once the Mars gravity well was sensed) and Mars ephemeris errors. In the event that the predicted landing site drifted from the target ellipse, a contingency maneuver (TCM-5) would be decided upon at either entry -11 or entry -7.5 hours (see Fig. 12). Because this maneuver would occur so close to entry, a customized maneuver design could not be performed, (as was done for TCMs 1-4). Instead, in each of the TCM-5 opportunities, the flight team had to decide whether to activate a command sequence from a pre-defined set already loaded on the flight system. In this manner, through proper sequence selection, the predicted landing site could be moved in downtrack and crosstrack. 
Figure 16 shows how the predicted landing site varied as the spacecraft approached Mars. Three-sigma ellipses at entry -24 , entry -13 , and entry -9 hours are shown. The last two ellipses represent the flight team's knowledge at the time of the two TCM-5 decision windows. Each of the TCM-5 landed prediction ellipses is approximately $100 \times 15 \mathrm{~km}$. While the best-estimated trajectory was predicted to be more shallow (an entry flight-path angle of $-13.9 \mathrm{deg}$ ) than just after TCM-4, the decision was made not to perform a TCM-5. This decision was a result of: (1) a majority of the TCM-5 predicted landed ellipses lying within the science requirement, (2) the science team not strongly objecting to a small overshoot of the desired ellipse, (3) the navigation team's confidence that the predicted ellipses would significantly diminish in size (but not move in center) as the entry approached, (4) the small northeastern movement in the prediction ellipse from entry -13 to entry -9 hours, and (5) the small, but finite risk associated with doing a propulsive maneuver so close to Mars arrival.

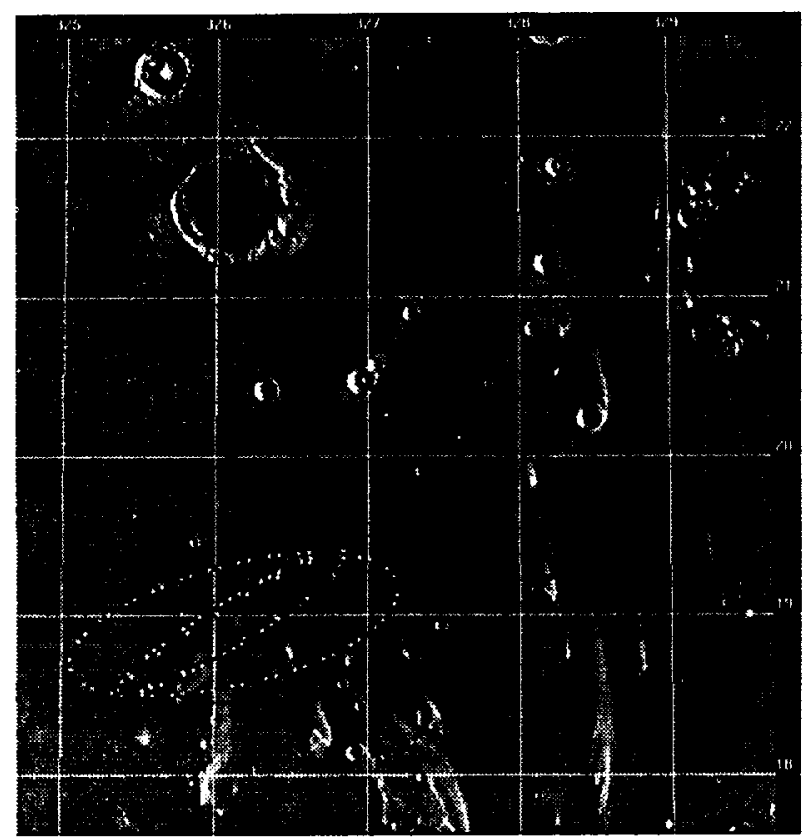

Fig. 16: Landing site predictions in the 24 hours preceding atmospheric entry.

As the spacecraft continued on toward Mars, the navigation team continued to refine its landing site predictions. Just prior to entry, the size of the predicted three-sigma ellipse had diminished considerably as shown in Fig. 17. The best-estimated flight path angle was $-14.06 \mathrm{deg}$. As a result, the navigation ellipse (excluding atmospheric and aerodynamic effects) was centered on a landing site of $19.22 \mathrm{deg} \mathrm{N}$ latitude, 33.4 degree W longitude. This ellipse was only $15 \times 7 \mathrm{~km}$ in

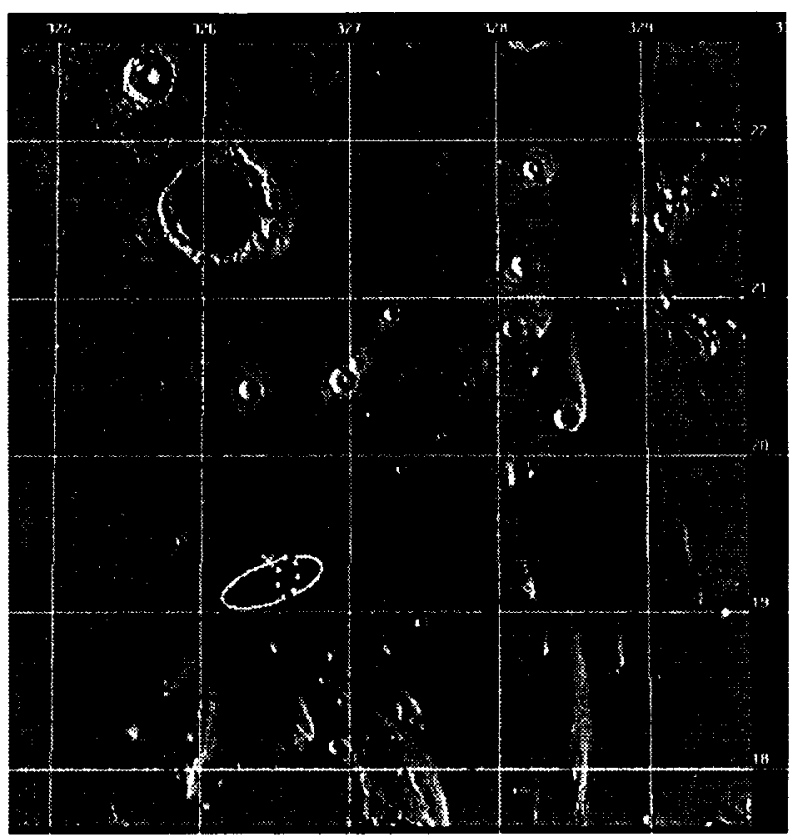

Fig. 17: Landing site predictions at atmospheric entry.

size and was no longer oriented with its semi-major axis aligned to the flight direction. This axis orientation change is indicative of a small degree of uncertainty in the entry flight-path angle.

The second ellipse shown in Fig. 17 represents the results of a Monte-Carlo analysis performed with the pre-entry orbit determination solution, including dispersions in the atmospheric flight-path. This ellipse is approximately $40 \times 15 \mathrm{~km}$, with its semi-major axis better aligned along the flight direction. It is centered on a landing site of $19.15 \mathrm{deg} N$ latitude, 33.51 degree $W$ longitude. Prior to entry -24 hours, atmospheric dispersions had been justifiably neglected in the navigation team's landing site predictions. However, as shown in Fig. 17, as knowledge of the entry state increased, the relative significance of the atmospheric flight dispersions also increased. These dispersions, caused by aerodynamic and atmospheric uncertainty, more than doubled the size of the final landing ellipse prediction.

The landing site determined by the Pathfinder science team once the spacecraft was safely on the Mars surface is also denoted in Fig. 17. This landed estimate was determined using the lander images to triangulate from observed surface features (craters, knobs, and peaks) as shown in Fig. 18. The science team landed estimate (19.33 deg N latitude, $33.55 \mathrm{deg} \mathrm{W}$ longitude) places the spacecraft just $27 \mathrm{~km}$ from the navigation target, the center of the science requirement ellipse. A small discrepancy (approximately $5 \mathrm{~km}$ ) between the final pre- 


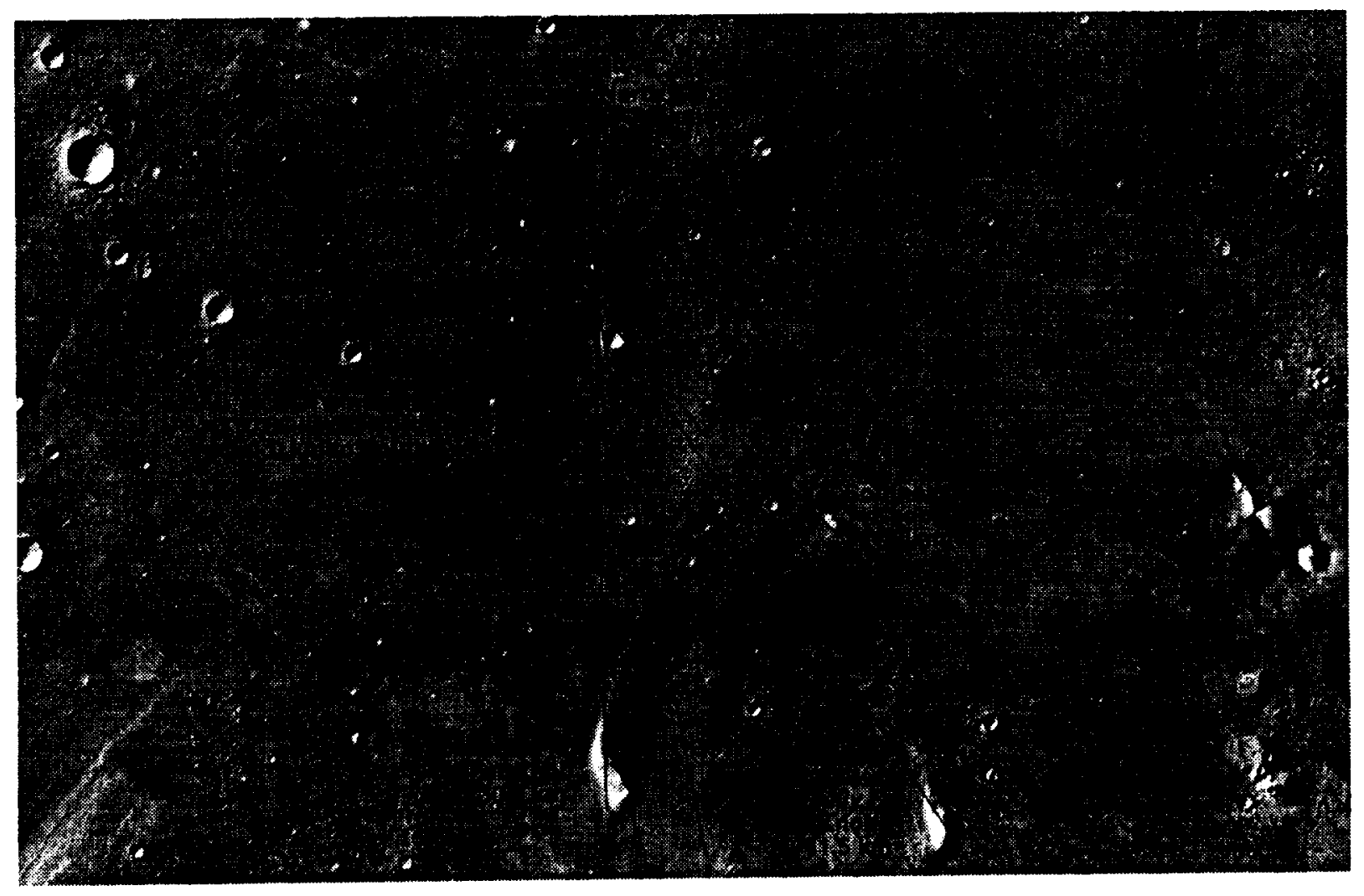

Fig. 18: Science team determination of Pathfinder landed site.

entry landed predictions and post-flight position reckoning exists. A majority of this error is believed to result from map-tie errors where the Mars surface features are not accurately reflected in an analytical latitude/longitude map. Additionally, a post-flight reconstruction analysis of the accelerometer data ${ }^{5}$ has indicated that the spacecraft may have bounced/rolled as much as $1 \mathrm{~km}$ before the airbag system stopped. This theory has been corroborated by evidence produced by the Pathfinder imager which has located an object believed to be the Pathfinder backshell $1.2 \mathrm{~km}$ southeast of the lander. Finding the backshell in this direction (an azimuth angle of $143 \mathrm{deg}$ ) further reduces the difference between the preentry and post-flight landing site predictions.

\section{PARACHUTE DEPLOYMENT ALGORITHM SYSTEM PERFORMANCE}

Engineering reconstruction of the Pathfinder entry, descent, and landing system performance ${ }^{5}$ is a critical legacy of this technology demonstration mission with significant implications for future exploration (e.g., Mars 98 lander, Mars 01 lander, Mars 01 orbiter, etc.). Atmospheric flight data from two sets of accelerometers, the radar-altimeter, and pressure and temperature sensors were measured and have been returned from the spacecraft.
Analysis of the accelerometer measurements conclusively demonstrates that the parachute was deployed based on the primary algorithm. Post-flight processing of the recorded accelerometer data shows that the vehicle passed through $5 \mathrm{~g}$ at $58.29 \mathrm{sec}$ after encountering the atmosphere. From the flight data, a $\mathrm{g}_{2}$ deceleration of $12.482 \mathrm{~g}$ is observed, yielding a $\mathrm{t}_{\mathrm{go}}$ of $101.08 \mathrm{sec}$ and a parachute deployment $171.37 \mathrm{sec}$ past the atmospheric interface. In contrast, the fixed-time backup parameter would have deployed the parachute at $164.11 \mathrm{sec}$ (see discussion regarding Table 2).

Figures 19 and 20 present the vehicle deceleration as a function of time from the atmospheric interface, taken directly from the accelerometer readings. These measurements are indicated in Fig. 20 from which the $32 \mathrm{~Hz}$ sampling rate is evident. The downward spike in the entry vehicle deceleration, seen between the accelerometer samples at times 171.375 and 171.406 , marks the firing of the parachute mortar. This temporary but significant acceleration (decrease in deceleration) is a result of the downward force imparted to the entry vehicle as the parachute mortar fired upward through the backshell. Parachute inflation required roughly $1.25 \mathrm{sec}$, with a maximum parachute snatch load of approximately $6.5 \mathrm{~g}$. Preliminary indications from the trajectory reconstruction 


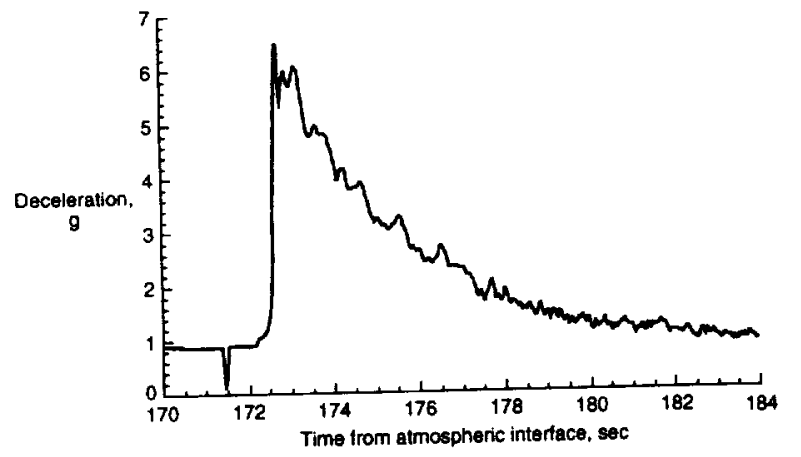

Fig. 19: Parachute deployment dynamics extracted from Pathfinder flight data.

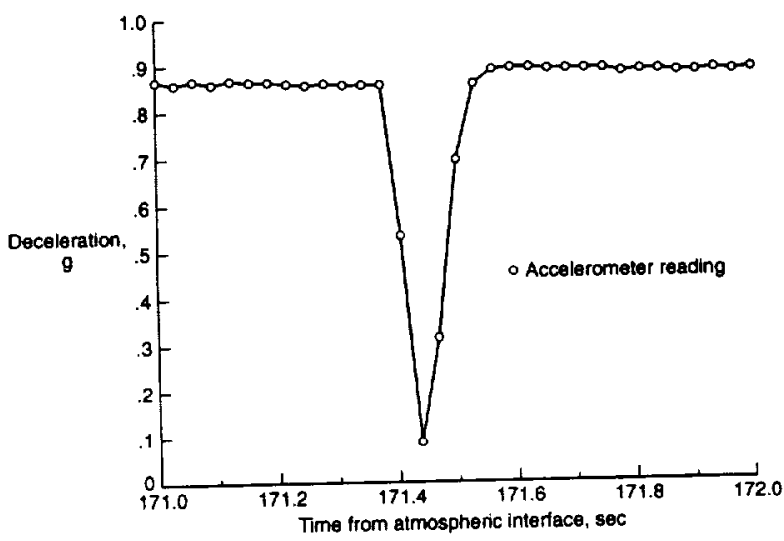

Fig. 20: Time of parachute mortar firing extracted from Pathfinder flight data.

analysis indicate that the parachute deployment altitude was approximately $7.9 \mathrm{~km}$ above the Mars reference ellipsoid (9.5 $\mathrm{km}$ above the surface) at a dynamic pressure of approximately $588 \mathrm{~N} / \mathrm{m}^{2}$ and a Mach number of 1.71 . This is extremely close to the parachute deployment design target; hence, the primary parachute deployment algorithm is believed to have performed well.

It is also interesting to note that the original fixedtime backup parachute deployment time, prior to parameter update process $\# 1$, would have resulted in a deployed parachute $16.2 \mathrm{sec}$ early at a dynamic pressure close to $850 \mathrm{~N} / \mathrm{m}^{2}$ (well above the design limit of $703 \mathrm{~N} / \mathrm{m}^{2}$ ). However, after modification during parameter update \#1, the backup fixed-time deployment would have occurred $7.3 \mathrm{sec}$ early at a dynamic pressure of approximately $695 \mathrm{~N} / \mathrm{m}^{2}$. This demonstrates that the parameter update process performed by the operations navigation team in the final days of interplanetary cruise increased the probability of mission success.

\section{SUMMARY}

On July 4, 1997, the Pathfinder spacecraft successfully landed on the surface of Mars. After a complex entry, descent, and landing process, the system landed just $27 \mathrm{~km}$ from its target point. In the present paper, the atmospheric entry and approach navigation activities required in support of this mission have been discussed. In particular, the flight software parameter update and landing site prediction processes performed by the Pathfinder operations navigation team were described.

The final set of flight software parameters was relayed to the Pathfinder spacecraft following the first parameter update process on July 2, at 11:00 pm PDT. This change set included modification of parameters affecting both the primary and backup parachute deployment algorithms. Although EDL parameter update 2-4 were all performed, no further updates were deemed necessary by the operations team. Preliminary evaluation of the accelerometer flight data indicates that the Pathfinder parachute deploy mortar was activated by the primary software algorithm at the appropriate conditions $\left(588 \mathrm{~N} / \mathrm{m}^{2}\right.$ and a Mach number of 1.71). This performance validates the design of the parachute deployment software algorithm. Furthermore, post-flight analysis has demonstrated that without the software parameter update and on the backup timer, the parachute deployment design constraints would have been significantly exceeded (a dynamic pressure close to $850 \mathrm{~N} / \mathrm{m}^{2}$ ). Hence, the probability of mission success was increased through the update process.

As the spacecraft approached Mars, the operations navigation team continued to refine its landing site predictions. At the two TCM-5 decision opportunities the predicted landing ellipse was approximately $100 \times 15 \mathrm{~km}$ in size and largely within the science requirement region. As a result, this contingency maneuver was not performed. As the spacecraft continued its Mars approach, the size and orientation of the predicted landed ellipse dramatically changed. At the time of entry, the predicted three-sigma landed ellipse size was $15 \times 7 \mathrm{~km}$, neglecting aerodynamic and atmospheric uncertainty.

At entry, the three-sigma flight-path angle uncertainty was $" 0.05 \mathrm{deg}$, centered on a nominal value of -14.06 deg. With such a small uncertainty on the entry state, the effect of aerodynamic and atmospheric uncertainties on the flight path was shown to be significant. With these uncertainties included, a six-degree-of-freedom Monte-Carlo analysis resulted in a three-sigma landed ellipse estimate of $40 \times 15 \mathrm{~km}$. The center of this estimate is within $0.5 \mathrm{~km}$ in downtrack position of the postflight landing estimate produced by the Pathfinder sci- 
ence team (with a crosstrack difference of approximately $5 \mathrm{~km}$ ), demonstrating the importance of atmospheric flight modeling to precision-landing site prediction. The remaining crosstrack difference is postulated to be a result of map-tie errors in which the Mars surface features are not accurately represented in the analytic map.

\section{ACKNOWLEDGMENTS}

The authors would like to thank R. Blanchard of NASA Langley Research Center and Dr. S. Thurman of the Jet Propulsion Laboratory for their insight regarding the Pathfinder flight data and the entire Pathfinder operations team for a job well done.

\section{REFERENCES}

${ }^{1}$ Kallemeyn, P., Cook, R., Spear, A., and Golombek, M., "The Mars Pathfinder Mission," Paper C-3-6, 7th International Space Conference of Pacific Basin Societies, Nagasaki, Japan, July 14-18, 1997.

${ }^{2}$ Bourke, R., Golombek, M., Spear, A., and Sturms, F., "MESUR and its Role in an Evolutionary Mars Exploration Program," IAF Paper 92-0509, Aug. 1992.

${ }^{3}$ Lehman, D., Sutton, P., Sword, G., and McGee, D., "MESUR Technology Development," AIAA Paper 934191, Sept. 1993.

${ }^{4}$ Hubbard, G., Wercinski, P., Sarver, G., Hanel, R., and Ramos, R., "A Mars Environmental Survey (MESUR)Feasibility of a Low Cost Global Approach," IAF Paper 91-432, Oct. 1991.

${ }^{5}$ Spencer, D., et. al., "Mars Pathfinder Entry, Descent, and Landing Reconstruction," AIAA Paper, AAS/ALAA Space Flight Mechanics Meeting, Monterey, CA, Feb. 1998.

6"Mars Pathfinder Mission and Ares Vallis Landing Site," M. Golombek, editor, Journal of Geophysical Research, Vol. 102, No. E2, Feb. 1997.

${ }^{7}$ Golombek, M., Cook, R., Moore, H., and Parker, T., "Selection of the Mars Pathfinder landing site," Journal of Geophysical Research, Vol. 102, No. E2, pp. 3967-3988, Feb. 1997.

${ }^{8}$ Cook, R., and McNamee, J., "Mission Design for the Mars Environmental Survey," AAS 93-563, Aug. 1993.

${ }^{9}$ Kallemeyn, P., Vaughan, R., Spencer, D., and Helfrich, C., "The Mars Pathfinder Navigation System," AIAA 963656. July 1996.
${ }^{10}$ Engelund, W., Gnoffo, P., Cruz, C., Braun, R., and Weilmuenster, K., "Aerodynamic Characteristics of the Mars Pathfinder Atmospheric Entry Configuration," NASA TM (in preparation).

11 Atmospheric Entry Program, Jet Propulsion Laboratory, 1993.

${ }^{12}$ Peng, C., Tsang, S., Smith, K., Sabahi, D., Short, K., and Mauritz, A. "Model Correlation for Mars Pathfinder Entry, Descent, and Landing Simulation," Proceedings of the 1997 IEEE Aerospace Conference, Feb. 1997.

${ }^{13}$ Brauer, G., Cornick, D., and Stevenson, R., "Capabilities and Applications of the Program to Optimize Simulated Trajectories (POST)," NASA CR-2770, Feb. 1977.

${ }^{14}$ Vaughan, R., "Mars Pathfinder Project Planetary Constants and Models, Mars Pathfinder Project", JPL D-12947, The Jet Propulsion Laboratory, Dec. 1995.

${ }^{15}$ Clancy, R., Lee, S., Gladstone, G., McMillan, W., and Rousch, T., "A New Model of Mars Atmospheric Dust Based on Analysis of Ultraviolet Through Infrared Observation from Mariner-9, Viking, and Phobos," Joumal of Geophysical Research, Vol. 100, pp. 5251-5263, 1995.

${ }^{16}$ Personal communication, Ed Fallen, Pioneer Aerospace, 1995.

${ }^{17}$ Braun, R., Powell, R., Engelund, W., Gnoffo, Weilmuenster, K., and Mitcheltree, R., "Mars Pathfinder Six-Degree-of-Freedom Entry Analysis," Joumal of Spacecraft and Rockets, Vol. 32, No. 6, pp. 993-1000, 1995.

${ }^{18}$ Spencer, D., and Braun, R., "Mars Pathfinder Atmospheric Entry: Trajectory Design and Dispersion Analysis, " Joumal of Spacecraft and Rockets, Vol. 33, No. 5, pp. 670-676, 1996.

${ }^{19}$ Muirhead, B., "Mars Pathfinder Flight System Integration and Test," Proceedings of the 1997 IEEE Aerospace Conference, Feb. 1997.

${ }^{20}$ Singh, G., "Mars Pathfinder Accelerometer Algorithm," Jet Propulsion Laboratory, JPL IOM 3456-95-12, Mar. 1995.

${ }^{21}$ Spencer, D., "Mars Pathfinder Parachute Deployment Accelerometer Algorithm Parameters," Jet Propulsion Laboratory, JPL IOM 312/96.2-004, May 1996.

\footnotetext{
${ }^{22}$ Spencer, D., "Mars Pathfinder Parachute Fixed-Time Backup," Jet Propulsion Laboratory, JPL IOM 312/95.22059, April 1995.
} 


\section{-}

